\title{
How Our Neighborhoods Lost Food, and How They Can Get It Back
}

\section{Geoff Boeing}

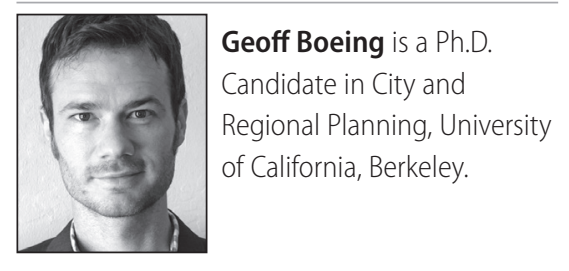

$\mathrm{D}$ oEs food matter in neighborhood planning and design? Should it matter? The answer is yes, but decades of planning policy and practice seem to suggest otherwise.

There are many proven benefits of healthy, accessible, affordable and sustainable food. Proper nourishment has been linked to better classroom performance. The US Centers for Disease Control and Prevention argue that walkable access to healthy food can reduce America's growing obesity and diabetes epidemics. Locally-sourced food reinforces better dietary habits as consumers connect with the value chain and perceive eating as a more natural process.

The benefits are clear, but most American neighborhoods do not support access to healthy food. On one hand, as the US Department of Agriculture frequently points out, many poor neighborhoods entirely lack healthy food retailers. On the other hand, wealthier suburbs tend to restrict commercial land uses in residential areas, exchanging walkable local food shops for car-reliant strip malls. This in turn is exacerbated by the growing disconnect between our cities and our rural food-producing regions.

\section{Lost Access to Healthy Food}

How did all of this happen? Two key factors are the specific evolution of the food industry and the pattern of urbanization in the United States. First, the evolution of large-scale industrial agriculture and food processing pushed food production facilities to a massive scale that would be impossible - let alone undesirable - to embed within cities. The ongoing monopolization of the industry has led to its domination by a small handful of corporations. Accordingly, farms themselves have reduced in number and increased in size, now often vertically integrated into a corporate superstructure and focused on producing a single commodity.

The second key factor is the pattern of American urbanization. In 1900, 40\% of Americans lived on farms. Today, fewer than $2 \%$ do. America urbanized over the past century according to the principles of rational modernism laid out by the likes of Le Corbusier and Robert Moses: command and 


Rational modernism
demanded "command
and control" to
arrange everything
in its right place.
Twentieth-century
urban planning and
design produced
monolithic,
monoculture
communities in which
civilization's functions
remain dramatically
segregated.
$\bullet$

control to arrange everything in its right place. Twentieth century urban planning and design produced monolithic, monoculture communities in which civilization's functions remain dramatically segregated.

Today, square miles of suburbs are zoned strictly residential, often with explicit restrictions against front yard agriculture and no allowances for food shops or local hubs. Downtowns are widely paved over or sporadically landscaped with ornamental plants. Food retailers have fled increasingly poor urban neighborhoods - the result of decades of discrimination and federal policy promoting white flight suburbanization - and resettled in new car-dependent suburbs.

Gone are the days of victory gardens and greengrocers selling fresh produce around the corner. Humans - an urban species - eat several times a day yet seem fixated on zoning food out of the urban experience. Food production has dismissively become the domain of our rural, agricultural, "fly-over" places, while urban policy and governance have developed under the assumption that this food supply from the hinterlands was forever a given.

Divorcing ourselves from millennia of collective experience, food today seems to appear in our supermarkets merely and inevitably for our consumption. There is little trace of how it got there. As rapid industrialization and coarsegrained zoning and planning eradicated food's origins from our daily lives, we began to value food as a set of abstract commodities that emphasized cheapness and distribution over nutrition.

\section{Fragility of the Physical Networks}

The physical networks that connect urbanites and suburbanites to their food are tenuous and prone to failure. Food delivery is reliant on complex systems of futures prices, overnight microloans, currency valuations and faith in credit: systems that nearly collapsed during the early hours of the 2008 financial crisis. Today, water scarcity and high fuel costs make food production and long-distance shipment ever more expensive. The ongoing California drought has transformed global food markets in the face of unprecedented water shortages. New York's brittle supply chains were recently exposed by the challenges of restocking food supplies in the aftermath of Superstorm Sandy.

Terrorism, earthquakes, hurricanes and wildfires can easily disrupt the roads and rails that link our cities to their precious food supplies. When the Big One finally strikes California, would your family rather live 300 miles away from its nearest food source, or just down the street from a community farm with days or even weeks of produce at hand? Further, the loss of crop species diversity for the sake of mass-production renders producers susceptible to exotic pests and locked into an arms race of powerful pesticides. A recent study by Khoury et al. in the "Proceedings of the National Academy of Sciences" highlights the global food supply's growing 
homogeneity and its negative

consequences for food security.

\section{Why Progressive Neighborhood Planning Matters}

Disconnecting our lives from local food is a problem that affects all of us in terms of massive risk, mortality rates and health care costs. But should it be the concern of neighborhood planners and urban designers? The past few years have given loud voice to the concerned citizens - such as those protesting UN Agenda 21 and regional planning - who fear government intervention into their communities as a loss of freedom of choice. Food policy and neighborhood design, however, require intervention to even begin to create choice in the first place.

Very few Americans can choose to live in neighborhoods with any local food supply, because such neighborhoods largely do not exist today. Further, housing affordability means that many lower- and middle-income families lack the choice to own multiple cars or live in an expensive, high-amenity neighborhood with a farmers' market or full-service grocery store. You are quite simply out of luck if your neighborhood is designed without access to healthy food, or if you do not have a car to drive several miles to the nearest grocery store. A free market is one with diverse choices. What we have here is a market failure mixed with a government failure - as University of Michigan planning scholar Jonathan Levine puts it - of bad policy, restrictive zoning and land use regulations that limit community health and resilience.

Fortunately, progressive urban planning offers some sensible solutions to these challenges. Promoting complete neighborhoods - with a range of housing options, green spaces, amenities, schedules and services - is increasingly popular in policy and practice. The city of Portland, Oregon recently introduced the goal of complete neighborhoods into its Portland Plan. Complete neighborhoods provide choices to a community, rather than a monoculture rooted in the passing fads of the day. It means that schools, restaurants, recreation and errands are within walking distance of everyone in the neighborhood. It means residents have a choice to shop for healthy food at a local market, participate in an urban farm and eat nutritious meals regardless of where they live. In sum, this provides a useful and flexible ethos for good urban planning: promote diverse and holistic neighborhoods to support the health and diversity of a community's population.

Success relies on more than just physical planning and design. Farmers' markets, urban agriculture and healthy food shops do not succeed when they are not supported by institutions and communities. Cities should coordinate their planning departments with food policy councils - as they have in Los Angeles - and local community development corporations to cultivate holistic programs. Zoning codes should be revised to permit healthy food retail and urban agriculture throughout our neighborhoods. Food hubs offer smaller farmers the benefits of aggregation, distribution and promotion to be competitive in growing markets, and should be sited to connect local and regional producers to urban markets that are otherwise hard to penetrate. Crucially, if we are to overcome the larger hurdles to local food, then a broader national consciousness must be yoked to the local food movements now challenging the powerful agriculture monopolies and the entrenched government interests that preserve them.

High-efficiency food production encouraged our species' rapid urbanization, but has also produced increasingly unhealthy neighborhoods, fragile logistical systems and inequitable distributions of the sustenance on which all humans equally rely. Healthy local food reconnects us with food systems as tangible processes. It creates a diversity of sourcing choices and supports resilient communities. Best of all, we need not repurpose valuable urban land to accommodate it: local food can be grown in our underutilized and interstitial spaces such as yards, medians, parks, vacant lots, rooftops and ornamental landscapes. With supportive zoning and policy, it can be sold in our neighborhood markets.

Yet local planning and physical design alone cannot restore healthy food to our neighborhoods. Local activism and action must be backed with stronger national leadership that counters the current stranglehold on food by industry and government. Nevertheless, healthy local food is a crucial component of good urban planning and is desperately needed in America today. $\quad \mathbf{p}^{2}$ 